\title{
WHY SHOULD I USE ADAS? ADVANCED DRIVER ASSISTANCE SYSTEMS AND THE ELDERLY: KNOWLEDGE, EXPERIENCE AND USAGE BARRIERS
}

\author{
Nicole Trübswetter \& Klaus Bengler \\ Technische Universität München, Institute of Ergonomics \\ Garching / Munich, Bavaria, Germany \\ Email: truebswetter@lfe.mw.tum.de
}

\begin{abstract}
Summary: A vast number of Advanced Driver Assistance Systems (ADAS) are commercially available, all of which have the potential to increase the safety and comfort of driving a car. Due to age-specific performance limitations, older drivers could benefit a great deal from such in-vehicle technologies, provided that they are purchased and used. Based on the results of several market research studies, awareness of ADAS is significantly higher than their usage rate, which is still very low. To analyze the discrepancy between awareness and willingness to use ADAS, 32 older car drivers were surveyed in a semi-structured interview study. This paper examines the knowledge, experience, and barriers toward the use of ADAS in the elderly.
\end{abstract}

\section{INTRODUCTION}

Due to the demographic changes in most industrial societies and the growing need for mobility, the proportion of older car drivers (aged 65 and over) is continuously increasing (OECD, 2001). In 2011, almost a quarter of all car users in Germany were over 60 years old. According to Winterhoff et al. (2009), more than a third of German car buyers are expected to be over 60 years old by the year 2020. Although older drivers are a statistically safe group compared to any other age group, their accident risk is increasing enormously by high age (70+ years). Due to the growth of older road users there are new challenges ahead in the field of roadworthiness. One of the most important steps is to support older drivers by introducing infrastructural, technological, and behavioral measures for retaining mobility up to advanced age (Coughlin \& D`Ambrosio, 2012). The automotive industry has developed and launched a variety of Advanced Driver Assistance Systems (ADAS). Many of these systems have the potential to compensate agespecific performance limitations in older adults, such as diminishing sensory perception, reduced information processing capacity and increased reaction time in complex situations (Fisk, Rogers, Charness, Czaja, \& Sharit, 2009; Schieber, 2006).

A survey at the Institute of Ergonomics at the Technische Universität München asked 265 car drivers about their experience of accident-related traffic situations, and their needs and desires for technical support. It revealed that drivers would like support when changing lanes, turning or overtaking, detecting potentially hazardous situations, speed and distance control, as well as when driving in the dark and at dusk (Trübswetter \& Bengler, 2011). Both the safety and comfort of the driver could be enhanced by ADAS provided that such systems are purchased and used. Based on the results of several market research studies, the current usage rate of these assistive technologies is still very low (European Commission, 2006; Wallentowitz \& Neunzig, 2005; Langwieder et al., 2012). What is the reason for the poor acceptance of ADAS? 
Several studies have investigated the acceptance of in-vehicle systems (van der Laan, 1997; Adell, 2009; Arndt \& Engeln, 2011) and all come to the same conclusion: The acceptance of an in-vehicle system is an important precondition for its use, because the driver is the one who decides whether or not to use a particular system. A common definition of acceptance cannot be found in the literature. Rather, there are different types and levels of technology acceptance which differ depending on the context of use. While earlier acceptance models, e.g. Technology Acceptance Model (TAM) (Davis, 1989), mainly focus on system usefulness and ease of use, later ones have been extended to account for drivers' attitudes, expectations, knowledge and understanding, perceived risk, perceived system disturbance, intention to purchase and willingness to pay (Venkatesh \& Davis, 2000; Adell, 2009). This shows that the definition of acceptance has changed from an attitudinal to a behavioral level, which emphasizes that a system is only accepted when it is used (Kollman, 2000). According to Adell (2009) "Acceptance is the degree to which an individual intends to use a system and, when available, to incorporate the system in his/her driving” (p. 31). This means the drivers' intention to use is the crucial factor for system acceptance.

The older drivers' attitude and intention to use ADAS has not sufficiently been explored so far. According to several research studies, user acceptance and utilization rates in older drivers in terms of technology in general is significantly lower than in younger and middle-aged users (Czaja \& Sharit, 1998). According to Pak \& McLaughlin (2011) it is a stereotype that older adults are neither interested nor capable of learning to use new technology. Their willingness to use strongly depends on the cost-benefit ratio, which is influenced by different factors such as usability, functionality, needs, perceived benefit and costs. Age-related differences in the number of technologies used mainly relate to the perception of technology needs, the effort to learn new technologies, cognitive and perceptual abilities, and personal attitudes and beliefs (Charness \& Boot, 2009). Adell (2009) found in her studies that older drivers evaluate their driving performance higher if they use an intelligent speed adaptation system (ISA). Furthermore, the perceived usefulness and satisfaction were greater in elderly than in younger drivers, still their willingness to keep the system after trial was not as high as that of the middle-aged drivers. This paper assesses the following questions: What is the reason for the low usage rate of ADAS? What knowledge and experience in dealing with ADAS do the elderly have? What kind of barriers are there in terms of use? In summary, the aim of this exploratory study was to examine elderly peoples' experience in using ADAS as well as existing usage barriers.

\section{METHOD}

To uncover the reasons for the discrepancy between the request for assistance and the low usage rate of ADAS, an interview study with 32 older car drivers was conducted. Since the research questions have not yet been adequately explored, a semi-structured interview study was chosen as evaluation method. Interviews afford the opportunity to collect detailed information about customer opinions and experiences in using the systems.

\section{Participants}

Participants were recruited using a subject database at the Technische Universität München as well as several postings in internet platforms, senior associations and newspaper advertisements. 
There were certain preconditions that the subjects had to fulfill, such as driving regularly, owning an upper mid-range or top-range car with optional equipment, and knowing at least one driver assistance system. All these criteria were reviewed by telephone screening. A total of 32 subjects participated at the interview study, 23 men and 9 women. The ages ranged from 60 to 80 years $(M=67 ; S D=5.6)$. The annual driving performance of the participants was relatively high. 16 subjects drove 10,000 to 20,000 kilometers per year, seven even more. The remaining subjects (9) covered an annual distance of 5,000 to 10,000 kilometers. All participants owned their own cars: two-thirds had one, nine had two, three had three and one even had four cars. The majority (14) tended to buy a new automobile every four to six years, nine subjects less often than every 6 years and nine every two to three years. The types of vehicle being used were very varied: BMW (7), VW (7), Audi (5), Mercedes (4), Volvo (2), Porsche (1), Lexus (1), Opel (1), Seat (1), Skoda (1), Ford (1), Lancia (1).

\section{Materials and Procedure}

Following ADAS were discussed during the interview study:

Table 1. Investigated Driver Assistance Systems

\begin{tabular}{|l|l|l|l|}
\hline Cruise Control (CC) & Lane Change Assist (LCA) & Night View Assist (NVA) & Park Distance Control (PDC) \\
\hline Adaptive Cruise Control (ACC) & Lane Keeping Assist (LKA) & High Beam Assist (HBA) & Park Assist (PA) \\
\hline Emergency Brake Assist (EBA) & Traffic Sign Recognition (TSR) & $\begin{array}{l}\text { Driver Drowsiness Detection } \\
\text { (DDDS) }\end{array}$ & Head-up Display (HUD) \\
\hline
\end{tabular}

The interview schedule, which was based on the results of several preliminary studies, consisted of 30 questions focusing on knowledge, attitude and experience with ADAS. This included the information processes prior to buying a new car, evaluation of awareness and experience of several systems, as well as identification of existing usage barriers. The aim was to obtain a comprehensive understanding of older drivers' assessments of ADAS. In total, 32 in-depth interviews were conducted by a trained interviewer and a recording clerk. All the interviews were tape-recorded and transcribed in full. To ensure common knowledge of ADAS in question, all subjects were given a brief explanation of each system in the second part of the interview, using pictures and short videos. The interview data were coded and analyzed using qualitative content analysis according to Mayring (2010). The aim of this method is to develop a structured category system. Once categorization was complete, all 32 transcripts were analyzed on the basis of encoding rules. In a further step, frequencies were calculated for each category. Finally, all the results were evaluated in the direction of the research questions.

\section{RESULTS}

\section{Awareness of ADAS}

Most of the subjects (27) knew the term "Driver Assistance Systems” (“Fahrerassistenzsystem”), nevertheless nine subjects could not give a definition. The responses to the question "What do you understand by driver assistance system” can be divided into three categories: support, comfort, and safety. The awareness of the different ADAS varied significantly. CC and PDC were the only technologies known by all participants. PA (94\%) and ACC (66\%) were also very popular. The remaining systems were known by around half of the subjects except HBA, which was only known by one third (31\%). The most common sources of information from which the 
participants had learned of ADAS were acquaintances (31\%), press (23\%), television (11\%), and car dealers (11\%). It is interesting that car dealers appeared to play a minor role, despite the fact that they are the major source of information to two-thirds of the subjects prior to buying a new car. Only 13 participants received information about ADAS during the sales phase. Many participants reported that no new in-vehicle systems have been presented to them and ADAS were not included in the sales pitch.

\section{System Experience and Ownership}

While experience of using CC (97\%) and PDC (88\%) was extensive, most of the other assistive technologies such as TSR (9\%), NV (6\%), ACC (6\%), and DDDS (3\%) were only being used by a small proportion of participants. User experience can be divided into "own system”, "tested system", and "no experience”. As shown in fig. 1, 75\% of subjects had CC and PDC. At least $19 \%$ had a car with HBA, which is a relatively high proportion in light of the low level of system awareness (31\%). The most commonly tested system was CC (22\%), followed by PA, HUD, and LCA (16\% each). Interestingly, none of the subjects who had tried LCA decided to purchase the system. Overall, it can be said that current experience with ADAS is very low despite a relatively high level of awareness.

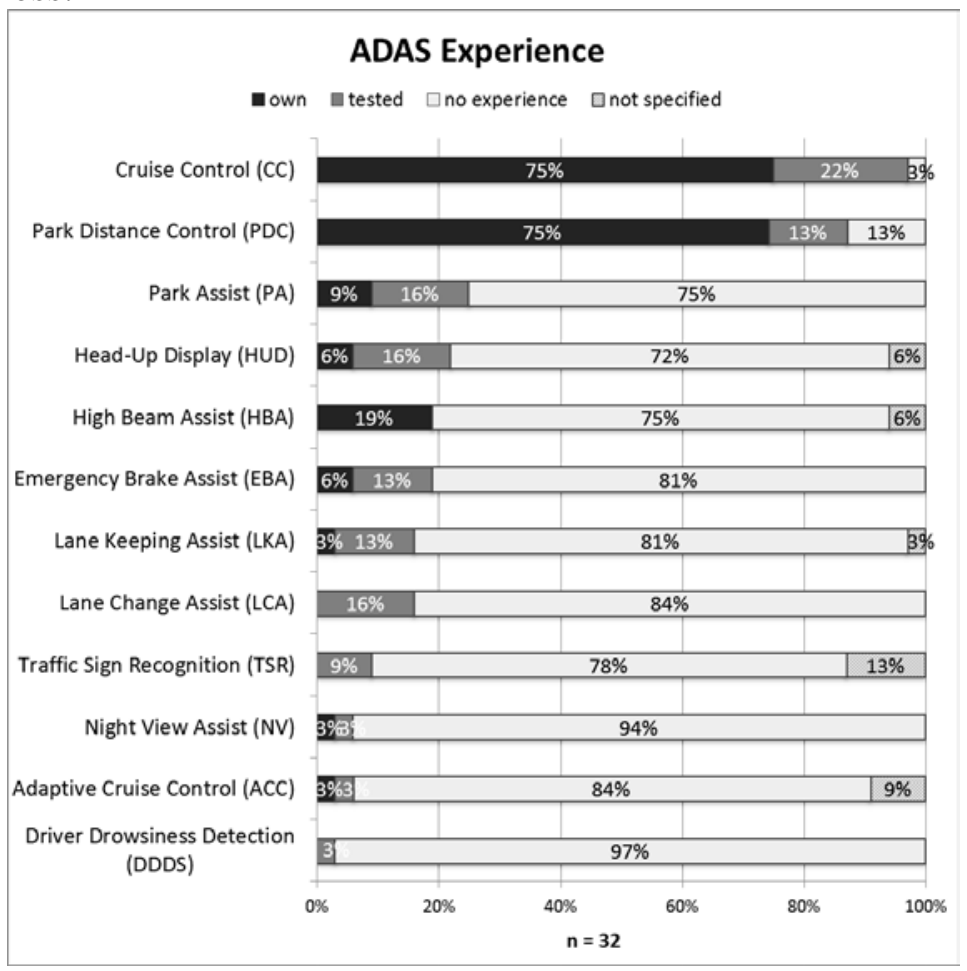

Figure 1. Experience of using each ADAS

\section{Usage Barriers}

In this paper usage barriers are defined as 'reasons for rejecting the use of driver assistant systems'. This counts for those who did not buy these systems as well as for those who do not use although they own them. Based on qualitative data analysis of the interview transcripts, 18 different barriers restricting the use of ADAS could be identified.

The barrier most commonly encountered in the interviews was a lack of perceived usefulness (32\%), implying that the subjects did not perceive a personal benefit from using the system. 
Several participants claimed that they did not need any assistance due either to good driving skills or to the lack of situations in which the systems would be of use. Another reason was the perception that system functionality or interaction design would not bring any benefit in critical situations. The lack of perceived usefulness was mainly reported in relation to DDDs, LDW, PA, and NVA. Another important barrier to the use of ADAS was functional limitation (9\%). This could entail functional deficits in the sensors or missing system properties as well as limited system reliability. Such a barrier was often mentioned in connection with PA, LDW, PDC, and CC. Interestingly, subjects often described perceived or anticipated limits of functionality despite never having tested the system before. A further frequently mentioned usage barrier was the costs of the systems ( $9 \%)$, in terms of both purchasing costs and maintenance costs. This refers primarily to PA, TSR, NVA, HUD, and ACC. Many participants reported that they would purchase ADAS if they were less expensive. A lot of subjects also complained about the system packages on offer, because they often wanted to buy only one system instead of an expensive package. The lack of system trust (8\%) was also found to affect the use of ADAS, in particular with LCA, EBA, DDDS and PA. Several participants stated that they were concerned about system failures or malfunctions. In safety-critical situations in particular, they would not rely on ADAS since they are not convinced that the systems are $100 \%$ reliable. It is clear that most of the doubts were based on lack of knowledge. Findings from the interview study indicated that undesired system feedback (7\%) also presented a barrier. Some participants complained about the kind of information presentation or warning strategy in combination with HUD, LCA, NVA, and PA. They indicated that the amount of information is rather distracting in critical traffic situations and suggested there was a danger of information overload. Also, acoustic or haptic feedback was perceived by some participants as disturbing or as inadequate as a warning strategy. Another usage barrier was lack of availability (6\%), i.e. an ADAS was not available for the purchased model of vehicle. A number of systems are only integrated in top-range and luxury class vehicles and therefore they cannot be selected in mid-range cars. Some interviewees considered the lack of availability to be the most relevant factor in inhibiting ADAS use. A fair number of participants described the risk of inattentiveness (5\%) as a barrier to using ADAS. They explained that use of the system could lead to inattention or a lack of concentration. This statement was often made in the context of LCA, CC, ACC, and LDW. A similar issue was the risk of driver distraction (4\%) from system feedback or system operation. This barrier primarily relates to systems with high visual information density such as HUD, NVA, and ACC. Other participants stated that they are afraid of a loss of control (4\%) through using assistance systems that engage in vehicle guidance, such as ACC, CC, PA, and EBA. As most of the subjects were less experienced in ADAS, they had no idea whether and how they could override the systems. For a few participants, inappropriate system design (3\%) is a barrier to the use, especially in connection with CC and ACC. This relates to system functionality and system behavior based on sensor capacity and algorithms. As indicated above, a lack of knowledge and experience was also mentioned as a usage barrier, mainly relating to EBA, TSR, ACC, and LDW. If knowledge of the system was inadequate, the subjects would reject the assistive technology. It should also be noted that many of the other reported barriers are attributable to lack of knowledge. Other barriers, such as security concerns, paternalism, incapacitation of the driver, loss of driving skills, fatigue /monotony, fear of use or complex handling, were only mentioned by one or two percent of participants and therefore they are not focus of further research. 


\section{DISCUSSION AND CONCLUSION}

The present research offers empirical data regarding the knowledge, experience and usage barriers to ADAS among elderly drivers. It can be concluded that the awareness of assistive functionalities is much higher than system experience and ownership. Some systems, such as PDC and CC, are familiar to and used by the majority of the interviewed sample. All the other functionalities had only been tested by a few subjects. This high rejection rate can be explained by a large number of usage barriers identified during the interview study.

The most common factor influencing the use of ADAS by older people, however, is a lack of perceived usefulness. If the participants do not perceive sufficient benefit from using the system they are not willing to use it. This finding matches the Technology Acceptance Model (TAM) (Davis, 1989) which suggests that perceived usefulness is one of the major determinants of a user's attitude and behavior towards the use of technology. According to Pak \& McLaughlin (2011), older adults are quite willing to overcome other barriers (e.g. cost, time to learn) if a system has obvious personal benefits. Other frequently mentioned usage barriers are the costs, functional limitations and lack of system trust. Ghazizadeh et al. (2012) showed in a study with on-board monitoring systems (OBMS) that trust into system plays an important role in determining drivers' intention to use ADAS. Nevertheless, older drivers need support in learning to use new technologies as well as information about the benefits they can gain from using ADAS. Coughlin \& D`Ambrosio (2012) and Koustanaï et al. (2012) found in their studies that training and experience is required for a better system understanding, including system capacities, benefits, and limitations. Koustanaï et al. (2012) demonstrated the positive effect of a simulator based system training on driver trust in the system and driver-system interaction. Moreover the presented findings require further investigation in order to identify additional influencing factors, such as personality traits. A second survey should encompass a larger sample for quantitative verification of the interview data. Furthermore, it is interesting to examine how user experience with ADAS will influence acceptance and willingness to use these systems. Based on the interview data, system training is likely to break down existing usage barriers. This hypothesis will be tested as part of a field experiment.

\section{REFERENCES}

Adell, E. (2009). Driver experience and acceptance of driver support systems - a case of speed adaptation. PhD thesis, Lund University, 2009

Arndt, S. \& Engeln, A. (2008). Prädiktoren der Akzeptanz von Fahrerassistenzsystemen. In Schade, J. \& Engeln, A. (Hrsg.), Fortschritte der Verkehrspsychologie: Beiträge vom 45. Kongress der Deutschen Gesellschaft für Psychologie, 313-338. Wiesbaden: Verlag für Sozialwissenschaften.

Charness, N., \& Boot, W. R. (2009). Aging and information technology use: Potential and barriers. Current Directions in Psychological Science, 18, 253-258.

Coughlin, J.F., D'Ambrosio, L.A., Eds. (2012). Aging America and Transportation: Personal Choices and Public Policy. New York: Springer Publishing Company.

Czaja, S. \& Sharit, J. (1993). Age differences in the performance of computer-based work. Psychology and Aging, 8, 59-67.

Davis, F. (1989). Perceived Usefulness, Perceived Ease of Use, and User Acceptance of Information Technology“. MIS Quarterly, 13 (3). 318-40. 
European Commission (2006). Special EUROBAROMETER 267 “USE OF INTELLIGENT SYSTEMS IN VEHICLES”, Wave 65.4, June-July 2006, TNS OPINION \& SOCIAL, Brussels

Fisk, A. D., Rogers, W. A., Charness, N., Czaja, S. J., \& Sharit, J. (2009). Designing for Older Adults: Principles and Creative Human Factors Approaches. Second Edition. Human Factors \& Aging Series. USA: CRC Press, Taylor \& Francis. Second Edition. Human Factors \& Aging Series. USA: CRC Press, Taylor \& Francis.

Ghazizadeh, M., Peng, Y., Lee, J. D. \& Boyle, L. (2012). Augmenting the Technology Acceptance Model with Trust: Commercial Drivers' Attitudes towards Monitoring and Feedback. In: Proceedings of the Human Factors and Ergonomics Society 2012 Annual Meeting 2012. 2286-2290.

Kollmann, T. (2000). Die Messung der Akzeptanz bei Telekommunikations-systemen. JBF Journal für Betriebswirtschaft, 50(2), 68-78. In: Franken, V., \& Lenz, B. (2007). User requirements for a multimodal routing system to support transport behaviour. Proceedings of the 6th European Congress and Exhibition on Intelligent Transport Systems and Services, Aalborg, Denmark.

Koustanaï, A.; Cavallo, V.; Delhomme, P. (2012). Simulator training with a forward collision warning system: Effects on driver-system interactions and driver trust. In: Human Factors: The Journal of the Human Factors and Ergonomics Society, Oct 2012; vol. 54 (5), 709-21.

Laan, J.D. van der et al. (1997). A simple procedure for the assessment of acceptance of advanced transport telematics. In: Transportation Research Part C: Emerging Technologies, 6 (1), 1-10.

Langwieder, K.; Bengler, K.; Maier, F. (2012). Effectiveness of Driver Assistance Systems and the Need of Promotion Regarding the Aim Vision Zero. In: Proceedings of the ICrash (International Crash Worthiness-Conference) 2012, Milano, July 18-20, 2012.

Mayring, P. (2010). Qualitative Inhaltsanalyse. Grundlagen und Techniken. 11. Auflage. Weinheim: Beltz Verlag.

OECD (2001). Aging and Transport. Mobility Needs and Safety Issues. Paris: OECD.

Pak, R. \& McLaughlin, A. (2011). Designing displays for older adults. Human Factors \& Aging Series. USA: CRC Press, Taylor \& Francis.

Schieber, F. (2006). Vision and aging. In Birren, J. E., Schaie, K. W. (Eds.), Handbook of the Psychology of Aging, 129-161. Amsterdam: Academic Press.

Trübswetter, N. \& Bengler, K. (2011). Systematische Modellierung des zukünftigen Unterstützungspotentials im Straßenverkehr. In: Gesellschaft für Arbeitswissenschaft (Hg.).57. Kongress der Gesellschaft für Arbeitswissenschaft. Dortmund: GfA-Press, 841-844.

Venkatesh, V. \& Davis, F.D. (2000). A Theoretical Extension of the Technology Acceptance Model: Four Longitutional Studies. In: Management Science, Vol.46, No2. 186-204.

Wallentowitz, H. \& Neunzig, D. (2005). Fahrerassistenzsysteme für ältere Menschen. Schriftenreihe Mobilität und Alter der Eugen-Otto-Butz Stiftung. In: Echterhoff, W. (Hrsg.). Mobilität und Alter. Strategien zur Sicherung der Mobilität älterer Menschen. Köln: Verlag TÜV Rheinland. 117-13.

Winterhoff, M., et. al. (2009). Zukunft der Mobilität 2020. Die Automobilindustrie im Umbruch? Arthur D. Little Report 2009. 